\title{
COUPLED FIELD ANALYSIS OF PRESSURE VESSEL FURNACE TUBE REDUCER USING FINITE ELEMENT METHOD
}

\author{
Tamil Mannan K. ${ }^{1}$, Saxena R. ${ }^{2}$, Murugavel Rathinam ${ }^{3}$, Sah P. L. ${ }^{4}$ \\ ${ }^{1}$ School of Engineering and Technology, Indira Gandhi Nantional Open University, New Delhi, India \\ ${ }^{2,4}$ Department of Mechanical Engineering, G.B.Pant University of Agriculture and Technology, Uttarakhand, India \\ ${ }^{3}$ Paavai Institutions, Namakkal, India \\ E-Mail: ${ }^{1}$ ktmannan@rediffmail.com, ktmannan@ignou.ac.in
}

\begin{abstract}
The reducer is a device used in boilers to distribute or collect steam water mixture from connected pipes used in the boilers are hollow cylindrical in shape, the connected reducers are more to suit the connected pipes with different diameters. The reducers in a boiler are subjected to the following loads: Internal steam pressure, Axial tensile load due to dead weight of connecting tubes, wind box, casing, buck stay and refractories, Furnace pressure load, Seismic load and Thermal stress due to uneven temperature distribution across the thickness of the reducer. Of these loads the effect of the internal pressure and axial tensile load due to dead load and thermal load on the reducer are considered in this analysis. Between two tubes of different diameters coactivity is ensured by reducer. The dimensions of the reducer are decided based on manufacturing facilities available and constraints. The reducer is checked to comply with the calculations and other requirements of relevant clause of statutory code, Indian Boiler Regulation (IBR). The aim of the analysis is to estimate exact stress and temperature distribution in reducer under actual working condition using Finite Element Method (FEM).
\end{abstract}

Key words: Stress and Temperature distribution, Finite Element Method, Solid Modeling, Failure Analysis.

\section{INTRODUCTION}

Reducer is located in furnace water wall. It provides smooth flow between connected tubes. The water walls are one of the most important components of boilers. They may be incorporated into the design of small shop assembled boiler as well as in the largest utility type units. Furnace water wall tubes are integrally concerned with all of its essential functions. As a link in the steam generating cycle, they are components of the pressure parts system [1].

Number of reducers employed varies depending upon the capacity of boiler. Usually, 268 reducers are employed in boiler of capacity $500 \mathrm{MW}$. Reducer is designed to withstand a maximum pressure of $18 \mathrm{~N} / \mathrm{mm} 2$ and dead load of $160 \mathrm{KN}$. It is reported that reducers are commercially manufactured by the swaging process and this process lead to reduction in thickness at smaller diameter section. It is made of SA210GRC material [2]. The thicknesses of $\varnothing 63.5 / 54 \mathrm{~mm}$ reducer are $5.9 \mathrm{~mm}$ at larger diameter and $6.55 \mathrm{~mm}$ at small diameter section.

To determine the reducer tube thickness is important to achieve thermodynamic requirements for particular type of furnace. The thickness provided in reducer is verified by strength calculation as per IBR No.338 (a) tube [3]. There is no accurate analytical solution to find the exact stress distribution in reducer. During manufacture of reducer, it was found that the thickness was less of more than permitted by codes [4].

Hence, it was decided to study the effect of thickness on the stress temperature distribution and strength of reducer. In this analysis, the stress in water wall tube reducer is computed using the classical finite element method.

\section{STRESSES IN REDUCER}

Reducer is used for connecting water wall tubes of different diameter. The steam pressure acts on inner surface areas of reducer. In addition, to this internal pressure of steam, the reducer tubes are subjected to most extreme fluctuations in temperature and pressure.

The thickness of reducers at different cross sections are slightly larger or smaller than the thickness estimated by using procedures laid down by the IBR No. 338 (a) tube[2]. It is therefore, necessary to compute the stresses developed in reducer under actual operating conditions and to study the effect of thickness on stress and strength of reducer. Hence, reducer is analyzed by using universally accepted finite element method. The computed stresses are compared with ASME SEC VIII DIV 2 allowable stress [4].

In this analysis, a typical $\varnothing 63.5 / 54 \mathrm{~mm}$ reducer is considered for analysis. The stress, temperature distribution and deformation of the reducer are obtained. These values are compared with permitted values for determining the acceptance or rejection of the reducer. The reducer is shown in Fig. 1.1 \& 1.2.

\section{DESIGN CONSIDERATIONS}

The reducer is used to connect water wall tubes of different diameter. Reducer is usually made of SA210 Grc material. The design of a reducer involves the determination of $r$ 


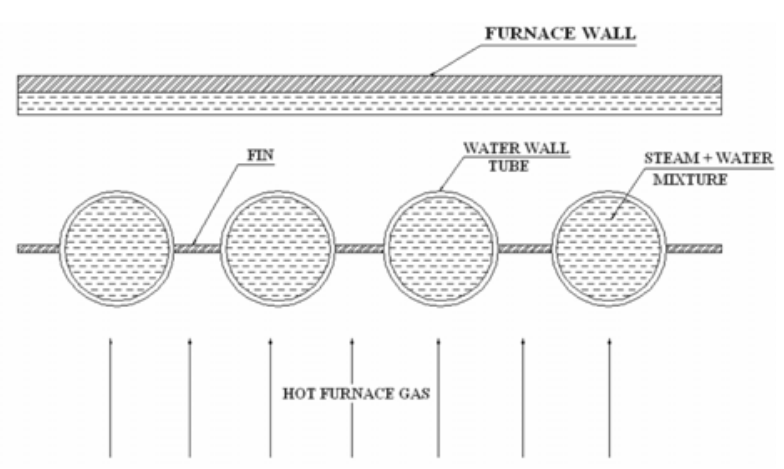

Fig. 1.1 Water wall tubes with fin

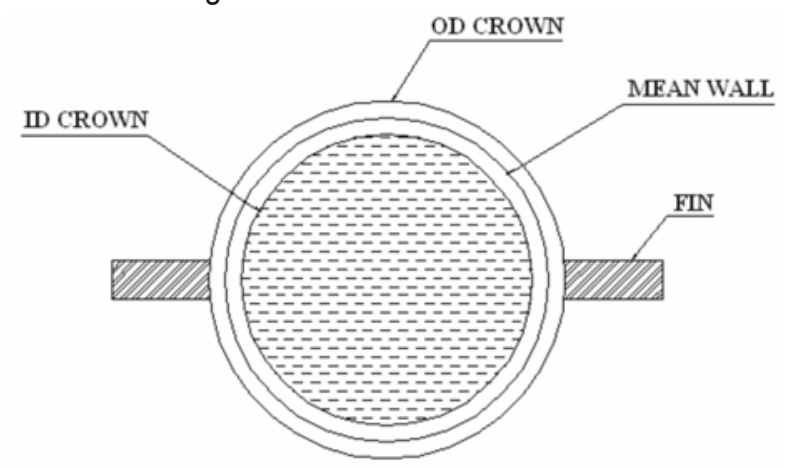

Fig. 1.2. Water wall tube thickness

outside diameter, wall thickness and length. It may be noted that the outside diameter of larger and smaller cylindrical portion of reducer are equal to outside diameter of corresponding connected tubes.

The inside diameter of the tube depends upon the quantity of fluid to the delivered. Design by rule involves use of formulae and rules to calculate basic wall thickness in order to keep nominal stress below the allowable stress values [5]. Design by analysis concept permits the use of higher allowable stress with no reduction in safety by rigorous analysis.

\section{FEM MODEL AND STRUCTURAL ANALYSIS}

The purpose of the using a solid model (Fig.1.3) is to relieve of the time-consuming task of building a complicated finite element model by direct generation. Allows to work with a relatively small number of data items, geometric operations such as dragging and rotations.

Supports the use of primitive areas and volumes and boolean operations for top down construction of model. Readily allows modifications to geometry. Solid modeling represents perhaps the real 3-D approach to design and drafting. The solid modeling and meshing operations can be used to speed up the creation of model for analysis.
Solid modeling objects satisfy the rigidity, homogeneous three dimensionality, finiteness and finite description requirements. The tetrahedral structural solid element (Fig.1.4) is the basic element for modeling three dimensional problems.

The element Solid 72 is well suited to model irregular meshes. The equivalent pressure is applied on the topside of the shell. The internal pressure is applied on inner side of the model. Structural boundary conditions at the base of reducer set the axial and radial displacements to zero. The boundary conditions and maximum induced structural stresses are presented in Fig.1.5. \& Fig.1.6.

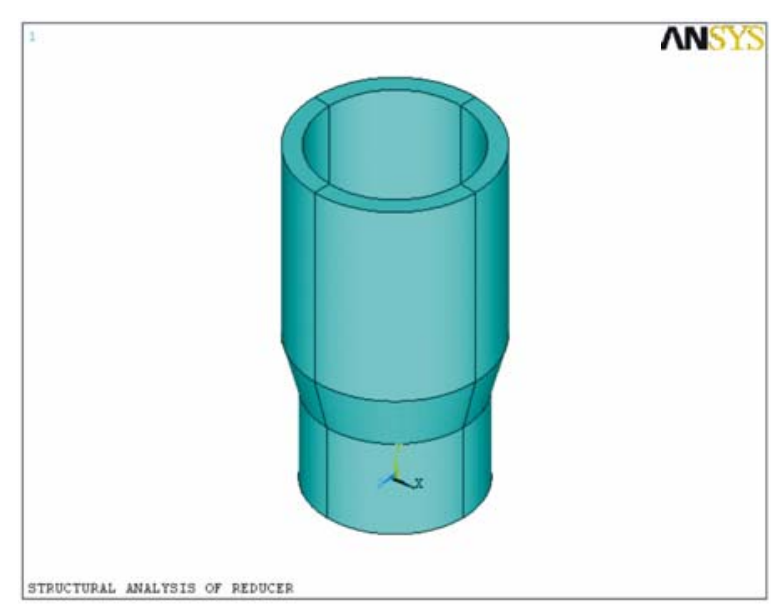

Fig. 1.3. The solid model

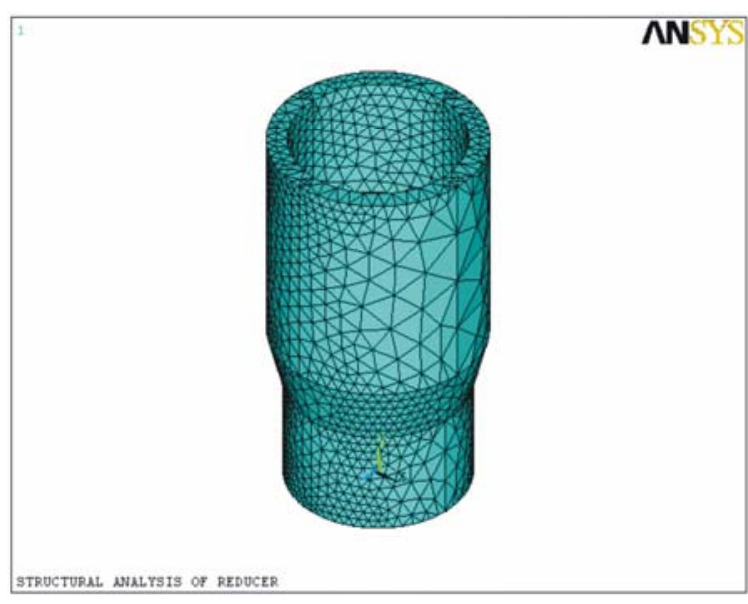

Fig. 1.4. The finite element mesh model 


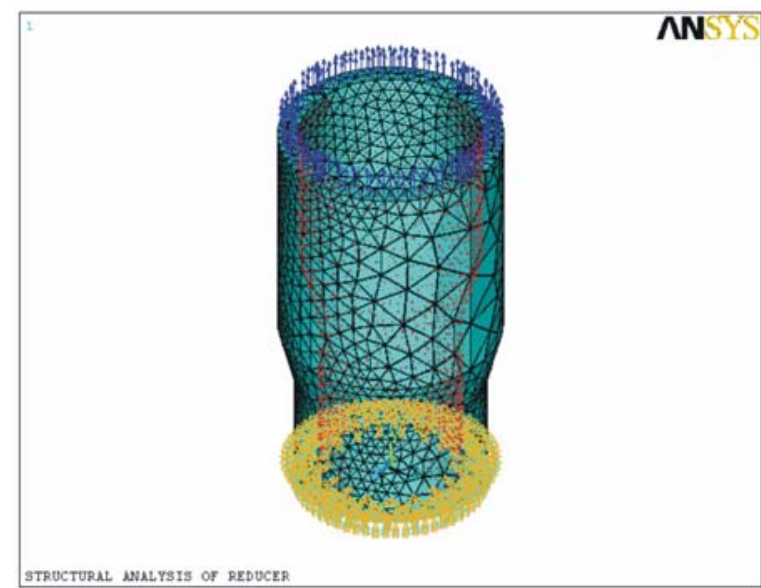

Fig. 1.5. The boundary conditions

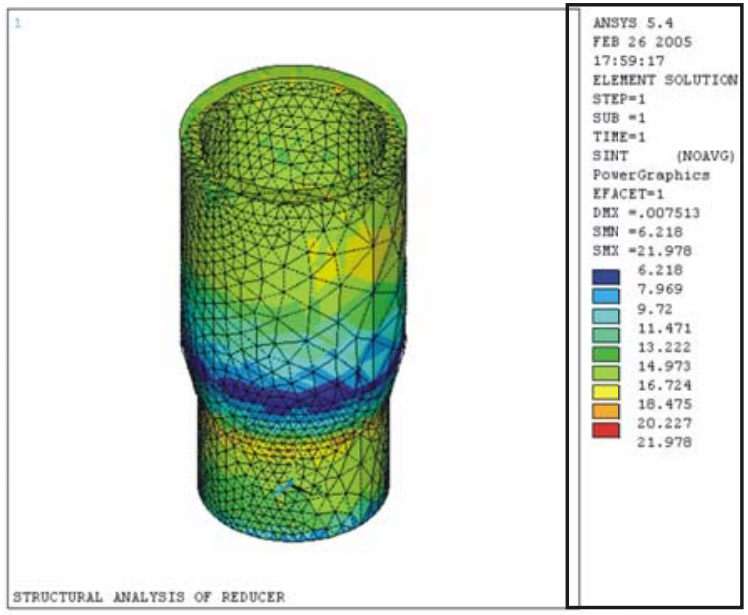

Fig. 1.6. Maximum induced stresses

\section{THERMAL ANALYSIS}

The FEA Command CONV is applied on inner side of the model and HFLUX \& CONV are applied on outer side of the model. Solid 87 3-D 10-Node tetrahedral thermal solid (fig.1.7) is well suited to model irregular meshes.

The element has one degree of freedom, temperature, at each node. The boundary conditions presented in Fig.1.8. and maximum induced thermal stresses are presented in Fig.1.9. \& Fig.1.10

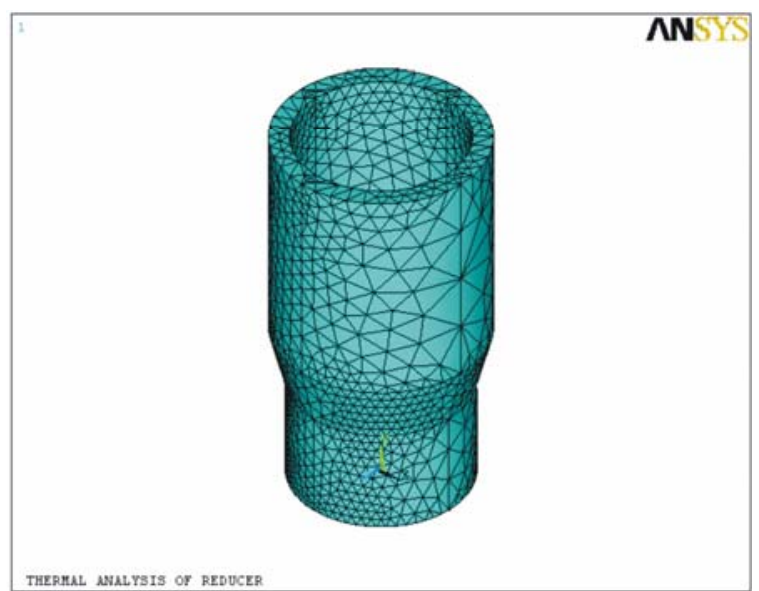

Fig. 1.7. Finite element mesh model

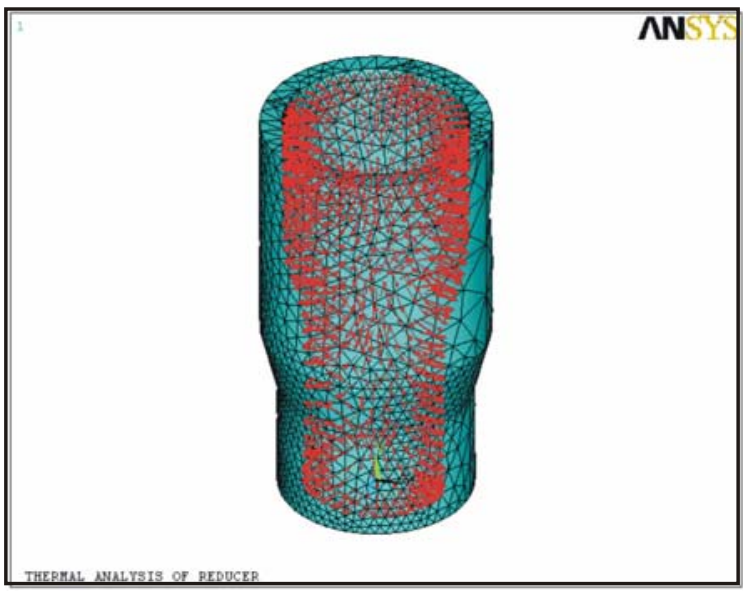

Fig. 1.8. The boundary conditions

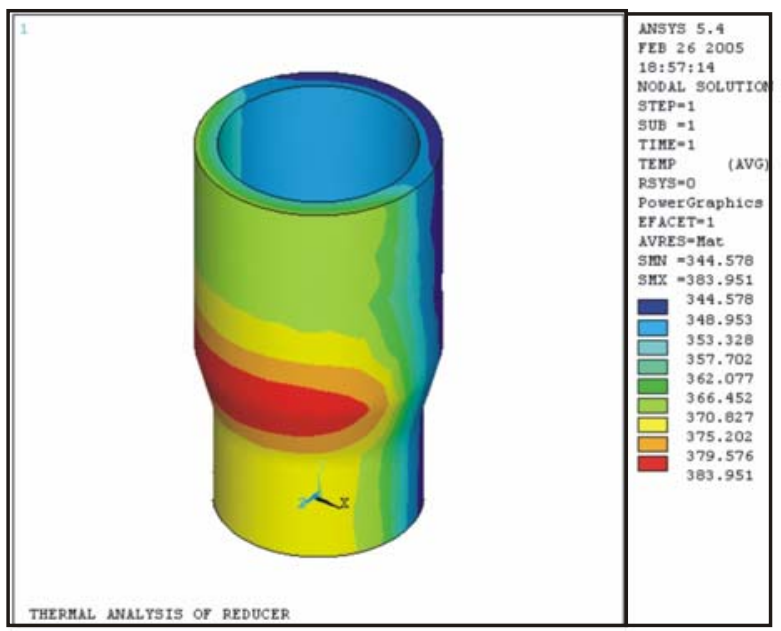

Fig. 1.9. Maximum induced stresses 


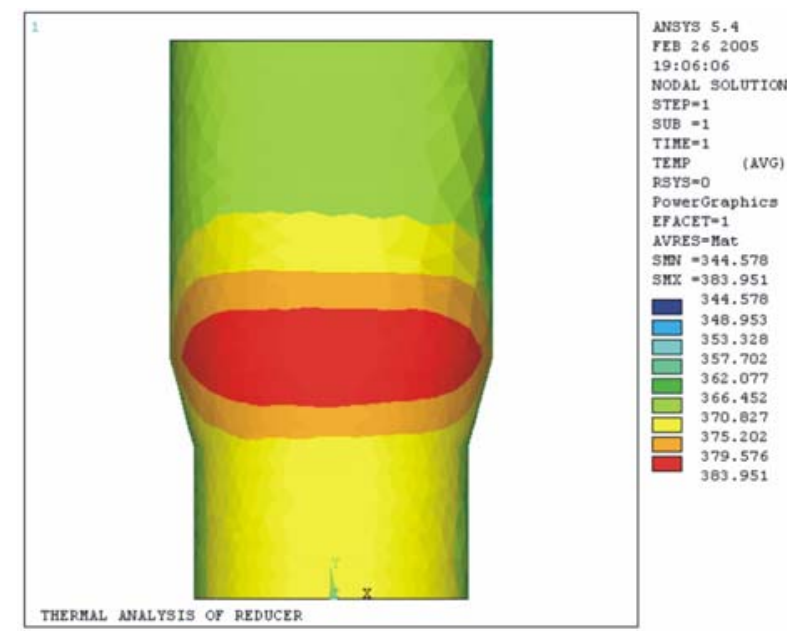

Fig. 1.10. Detailed view of maximum induced stresses

\section{RESULTS AND DISCUSSION}

From the structural analysis (Fig.1.6), it is found that stresses induced in the reducer are within acceptable limit less than $38 \mathrm{~kg} / \mathrm{mm} 2$. Therefore it is found that the design is safe. Naturally stress levels are higher considering external axial loading. Even then the stress levels are found below the yield stress.

From the thermal analysis (Fig.1.9 and 1.10), it is found that heat concentration is more at the neck portion of the reducer. This is possible due to localized increase in thickness at the neck portion.

\section{CONCLUSION}

The stresses induced in the reducer are complex and require three dimensional finite element analyses. The ANSYS macro can handle this kind of complex shapes easily. The stress levels are within acceptable limit as per
ASME, B 31.1 and Sec VIII Div 2. As such under the actual operating conditions the component would be safe. The maximum temperature redeveloped is $383.9510 \mathrm{C}$ which is less than the recommended operating of SA $210 \mathrm{Grc}$ Material.

\section{REFERENCES}

[1] J. F. Harvey, P.E, 1991, Theory \& Design of Pressure Vessels, CBS Publishers and Distributors, New Delhi.

[2] ASME Bolier \& Pressure Vessel Code I, II, and VIII Division $1 \& 2,1998$

[3] D. R.Moss, 1997, Pressure Vessel Design Manual," Gulf Publishing Company, Huston.

[4] K. J. Bathe, 1993, Finite Element Procedures, Prentice-Hall of India (P) Ltd., New Delhi.

[5] E. F. Megyesy, 1992, Pressure Vessel Hand Book Ninth Edition, PVHB Publishing Inc.

[6] E. Troiano, J. H. Underwood and A. P. Parker, 2006, Finite Element Investigation of Bauschinger Effect in High-Strength A 723 Pressure Vessel Steel, Journal of Pressure Vessel Technology, 128, pp 185-189.

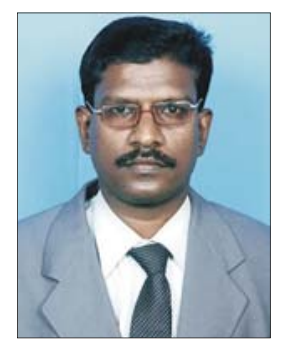

Dr.K.Tamil Mannan is a Doctorate from G.B.Pant University of Agriculture \& Technology, Uttarakhand and is a Reader at the Department of Mechanical Engineering, Indira Gandhi National Open University, New Delhi. He has over twelve years of teaching experience and has involved in the Research Activities in State and Central Universities. 